\title{
Data Clustering using Autoregressive Integrated Moving Average (ARIMA) model for Islamic Country Currency: An Econometrics method for Islamic Financial Engineering
}

\author{
Nashirah Abu Bakar ${ }^{1}$, Sofian Rosbi ${ }^{2}$ \\ ${ }^{l}$ Islamic Business School, College of Business, Universiti Utara Malaysia, Malaysia \\ ${ }^{2}$ School of Mechatronic Engineering, Universiti Malaysia Perlis, Malaysia
}

\begin{abstract}
-
Exchange rate is price of a nation's currency in terms of another currency. The value of exchange rate is important as one of the indicators to shows the strength of economic condition for particular country. This paper performed data clustering in analyzing the currency exchange rate which is 1 Malaysian Ringgit (MYR) to United States Dollar (USD). The method that is implemented in this study is Autoregressive Integrated Moving Average (ARIMA) model. This study performed stationary analysis, modeling analysis and diagnostics checking. In stationary evaluation process, the integration of order $1, I(1)$ is validated as stationary variable. The findings show ARIMA $(1,1,1)$ is suitable for clustering the data between January 2010 until April 2017.The importance of this findings is to provide economists and researchers understand the dynamic behavior of currency movement. In addition, further study can be implement in evaluating the determinants factors that contributes to the dynamic behavior of currency exchange rate.
\end{abstract}

Keywords - Data clustering, ARIMA model, Malaysian Ringgit, Islamic Financial Engineering

Date of Submission: 09 June 2017

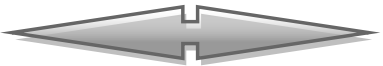

Date of Accepted: 17 June 2017

\section{INTRODUCTION}

In year of 2014 until 2017, Malaysian currency experienced low value of currency exchange rate with respect to United States Dollar. Therefore, in year of 2017, Central Bank of Malaysia (BNM) announced new method to improve the liquidity and encourages more domestic trade in Malaysian Ringgit. In process of stabilizing the Malaysian Ringgit exchange rate value, BNM mentioned that only retain up to $25 \%$ of export can proceeds in a foreign currency, while the balance must be converted into ringgit. This regulation gives a significant impact on the exchange rate in Malaysian market. In validating this new strategies, the estimation of Malaysian Ringgit exchange rate need to be monitor in high accuracy. The purpose of this monitoring is to increase the strength of Malaysia economic.

Exchange rate affect almost everyone in the economics including financial institutions, stock market, and others institution. If these various economics player can forecast future changes in exchange rate, they can modify future investment and restructure strategic planning. Forecast is one of the methods used to predict the fluctuations in exchange rate, but only a few of researches have investigates how statistical technique can improve forecasting method. As suggest by Jadevicius and Huston (2015)[1], ARIMA is a useful technique to assess broad market price changes. Government and central bank can use ARIMA modeling approach to forecast national house price inflation. Developers can employ this methodology to drive successful house-building program. Investor can incorporate forecasts from ARIMA models into investment strategy for timing purposes. Besides that, ARIMA model is a unique method because it does not construct either a single-equation or a simultaneous-equation model; but instead analyzes the probabilistic, or stochastic, properties of an economic time series. The ARIMA procedure analyzes and forecasts equally spaced univariate time series data, transfer function data, and intervention data. An ARIMA model predicts a value in a response time series as a linear combination of its own past values, past errors (also called shocks or innovations), and current and past values of other time series. (Al-Shiab, 2006)[2].

Currently, Islamic country was aggressive in promoting Islamic financial products and services. This is because the populations of Muslim people are increase and the demand for Islamic financial products and services also increase. Non-Muslim countries like Japan, United Kingdom also started introducing Islamic financial products and services. Thus, Malaysia as one of the member in Organization of Islamic Cooperation (OIC) countries with more than $60 \%$ of the population is a Muslim people also aggressive in promoting Islamic financial products and services. Apart from this Malaysia also established the world's first Sharia based commodity trading platform on the domestic stock exchange (Bursa Malaysia). This platform gives a significant impact on the sharia-compliant 
companies. Moreover, Islamic finance is also on the rise in new markets such as Syria, Lebanon, the U.K., Turkey and Canada (Abdul Razak and Abd Karim, 2008)[3]. This phenomenon gives high opportunities to the huge pool of Islamic capital. International Islamic banking assets with commercial banks were set to exceed US\$778bn in 2014. In particular, six markets - Qatar, Indonesia, Saudi Arabia, Malaysia, the United Arab Emirates (UAE) and Turkey - are heading toward touching US\$1.8tn by 2019 (Zarrouk, El Ghak and Al Haija, 2017)[4].

Islamic financial transaction must follow shariah law. All the transaction must be in line with Al-Quran and Al-Sunnah. Abu Bakar and Uzaki (2013)[5] mention that the basic understanding of Islamic financial transaction is the transaction must be free from any prohibited element of usury, uncertainty and gambling. Usury (riba) defines as an increase or excess in any exchange or sale of good or by virtue of loan without providing equivalent value to the other party. Uncertainty (gharar) refers to the activities that have elements of uncertainty in measure weight of goods, price of goods or deceiving the buyer on the price of goods. Gambling (maysir) is refers to the any activity that involves betting. The winner will take the entire bet and loser will lose his bet. Others prohibited elements, such as non-halal foods, drinks and immoral activities also must be absent. Thus it is important for Islamic financial institutional to understand the principles in shariah law. As highlight by Hussain et al. (2015)[6] three principles govern on Islamic financial transaction are principle of equity; principle of participation; and principle of ownership. Generally, there is no consensus neither in theoretical nor in empirical level regarding the direction of this relationship albeit the theory focus on unidirectional causality from exchange rates to stock prices (Tsagkanos and Siriopoulos, 2013)[7]. As investors, there are interested to forecast future trends for the economy fluctuation in order to determine the investment strategic. In the economic literature, there are many research papers that investigate the relationship between stock prices and exchange rates either in theoretical or empirical level. However, no prior academic work has analyzed the currency exchange rate between Malaysian Ringgit and United States Dollar. Therefore this study performs the ARIMA model in order to investigate the data clustering for currency exchange rate. The selected data of currency exchange rate which is 1 Malaysian Ringgit (MYR) to United States Dollar (USD). The period of analysis is arranged from January 2010 until April 2017.The total observations that involved in this analysis is 88 months observations.

\section{LITERATURE REVIEW}

Exchange rate is price of a nation's currency in terms of another currency. The value of exchange rate is important as one of the indicators to shows the strength of economic condition for particular country. Since the breakdown of the Bretton Woods system of fixed exchange rates in the early 1970s, forecast currency values has become crucial for many purposes such as international comparisons of incomes, earnings and the costs of living by international agencies, management and alignment of exchange rates by governments, and corporate financial decision making (Clements and Lan, 2010)[8]. Even though, it is widely agreed that forecast of exchange rate is difficult task because it was influenced by many factors. According to Meese and Rogoff (1983)[9] a random walk model would have predicted major-country exchange rate during the recent floating rate period. Random walk model has occupied center phase for many years, practitioners and researchers continue to employ a variety of techniques in an effort to beat the random walk. Clements and Lan (2010)[8] highlight three approaches of exchange rate forecasting; surveys, model-based approaches and the composite forecast approaches.

Forecasting is important part in economic analysis especially when it was involved with the fluctuation of price. There are many methods in forecasting models. One of the models applied in this study is ARIMA model. Al-Shiab (2006)[2] found that Amman Stock Exchange would continue to grow by $0.195 \%$ for the next seven days as the ARIMA model predicted. However, looking at the actual data over the same forecasted period, it seems that the Amman Stock Exchange performance declined on average by $-0.003 \%$, thus the prediction is failed to match market performance.

Balli and Elsamadisy (2012)[10] suggested the ARIMA model provides better estimates for short-term forecasts, because their finding show that this model are less than 100 million Qatari riayal for the short term currency in circulation forecast. El-Masry and Abdel-Salam (2007)[11] examine the effect of firm size and foreign operations on the exchange rate exposure of UK non-financial companies. They found that a higher percentage of UK firms are exposed to contemporaneous exchange rate changes than those reported in previous studies. UK firms' stock returns are more affected by changes in the Equally Weighted (EQW), and US\$ European currency unit exchange rate, and respond less significantly to the basket of 20 countries' currencies relative to the UK pound exchange rate. It is found that exchange rate exposure has more significant impact on stock returns of the large firms compared with the small and medium-sized companies.

\section{RESEARCH METHODOLOGY}

This study using an autoregressive integrated moving average (ARIMA) model to perform data clustering. 3.1 Autoregressive (AR) model 
An autoregressive (AR) model is a representation of a type of random process. It is used to describe certain time-varying processes in time series data. The autoregressive model specifies that the output variable depends linearly on its own previous values and on a stochastic term (an imperfectly predictable term). Thus, the model is in the form of a stochastic difference equation.

In probability and statistics, a random variable, random quantity or stochastic variable is a variable quantity whose value depends on possible outcomes. As a function, a random variable is required to be measurable, which rules out certain pathological cases where the quantity which the random variable returns is infinitely sensitive to small changes in the outcome.

A random variable is defined as a function that maps outcomes to numerical quantities, typically real numbers. In this sense, it is a procedure for assigning a numerical quantity to each physical outcome, and, contrary to its name, this procedure itself is neither random nor variable.

A random variable has a probability distribution, which specifies the probability that its value falls in any given interval. Random variables can be discrete, that is, taking any of a specified finite or countable list of values, endowed with a probability mass function characteristic of the random variable's probability distribution; or continuous, taking any numerical value in an interval or collection of intervals, via a probability density function that is characteristic of the random variable's probability distribution; or a mixture of both types.

The notation $\operatorname{AR}(p)$ indicates an autoregressive model of order $p$. The $\operatorname{AR}(p)$ model is defined as:

$$
\begin{aligned}
& X_{t}=c+\varphi_{1} X_{t-1}+\ldots+\varphi_{p} X_{t-p}+\varepsilon_{t} \\
& X_{t}=c+\sum_{i=1}^{p} \varphi_{i} X_{t-i}+\varepsilon_{t}
\end{aligned}
$$

where $\varphi_{i}, \ldots, \varphi_{p}$ the parameters of the model, $c$ is constant, and $\varepsilon_{t}$ is white noise.

An autoregressive model can thus be viewed as the output of an all-pole infinite impulse response filter whose input is white noise. Some parameter constraints are necessary for the model to remain wide-sense stationary. For example, processes in the AR (1) model with $\left|\varphi_{1}\right| \geq 1$ are not stationary. More generally, for an AR $(p)$ model to be wide-sense stationary, the roots of the polynomial $z^{p}-\sum_{i=1}^{p} \varphi_{i} z^{p-i}$ must lie within the unit circle. Each root $z_{i}$ must satisfy the condition of $\left|z_{i}\right|<1$.

\subsection{Moving average (MA) model}

In time series analysis, the moving-average (MA) model is a common approach for modeling univariate time series. The moving-average model specifies that the output variable depends linearly on the current and various past values of a stochastic (imperfectly predictable) term.

The notation MA $(q)$ refers to the moving average model of order $q$ :

$$
\begin{aligned}
& X_{t}=\mu+\varepsilon_{t}+\theta_{1} \varepsilon_{t-1}+\ldots+\theta_{q} \varepsilon_{t-q} \\
& X_{t}=\mu+\varepsilon_{t}+\sum_{i=1}^{q} \theta_{i} \varepsilon_{t-i}
\end{aligned}
$$

where $\mu$ is the mean of the series, $\theta_{1}, \ldots, \theta_{q}$ are the parameters of the model, and $\varepsilon_{t}, \varepsilon_{t-1}, \ldots, \varepsilon_{t-q}$ are white noise error terms. The value of $q$ is called the order of the MA model.

In discrete time, white noise is a discrete signal whose samples are regarded as a sequence of serially uncorrelated random variables with zero mean and finite variance; a single realization of white noise is a random shock. Depending on the context, one may also require that the samples be independent and have identical probability distribution (in other words i.i.d. is the simplest representative of the white noise). In particular, if each sample has a normal distribution with zero mean, the signal is said to be Gaussian white noise.

Thus, a moving-average model is conceptually a linear regression of the current value of the series against current and previous (unobserved) white noise error terms or random shocks. The random shocks at each point are assumed to be mutually independent and to come from the same distribution, typically a normal distribution, with location at zero and constant scale.

The moving-average model is essentially a finite impulse response filter applied to white noise, with some additional interpretation placed on it. The role of the random shocks in the MA model differs from their role in the autoregressive (AR) model in two ways. First, they are propagated to future values of the time series directly: for example, $\varepsilon_{t-1}$ appears directly on the right side of the equation for $X_{t}$. In contrast, in an AR model $\varepsilon_{t-1}$ does not 
appear on the right side of the equation, but it does appear on the right side of the $X_{t-1}$ equation, and $X_{t-1}$ appears on the right side of the $X_{t}$ equation, giving only an indirect effect of $\varepsilon_{t-1}$ on $X_{t}$. Second, in the MA model a shock affects $X$ values only for the current period and $q$ periods into the future; in contrast, in the AR model a shock affects $X$ values infinitely far into the future, because $\varepsilon_{t}$ affects $X_{t}$ until $X_{t-p}$.

In statistics and econometrics one often assumes that an observed series of data values is the sum of a series of values generated by a deterministic linear process, depending on certain independent (explanatory) variables, and on a series of random noise values. Then regression analysis is used to infer the parameters of the model process from the observed data, e.g. by ordinary least squares, and to test the null hypothesis that each of the parameters is zero against the alternative hypothesis that it is non-zero. Hypothesis testing typically assumes that the noise values are mutually uncorrelated with zero mean and the same Gaussian probability distribution - in other words, that the noise is white. If there is non-zero correlation between the noise values underlying different observations then the estimated model parameters are still unbiased, but estimates of their uncertainties (such as confidence intervals) will be biased (not accurate on average). This is also true if the noise is exhibits heteroskedasticity - that is, if it has different variances for different data points.

\subsection{Autoregressive-moving-average (ARMA) model}

In the statistical analysis of time series, autoregressive-moving-average (ARMA) models provide a parsimonious description of a (weakly) stationary stochastic process in terms of two polynomials, one for the autoregression and the second for the moving average.

Given a time series of data $X_{t}$, the ARMA model is a tool for understanding and predicting future values in this series. The model consists of two parts, an autoregressive (AR) part and a moving average (MA) part. The AR part involves regress the variable on its own lagged values. The MA part involves modeling the error term as a linear combination of error terms occurring contemporaneously and at various times in the past.

The notation ARMA $(p, q)$ refers to the model with $p$ autoregressive terms and $q$ moving-average terms. This model contains the AR $(p)$ and MA $(q)$ models,

$$
X_{t}=c+\sum_{i=1}^{p} \varphi_{i} X_{t-i}+\varepsilon_{t}+\mu+\varepsilon_{t}+\sum_{i=1}^{q} \theta_{i} \varepsilon_{t-i}
$$

where $\mu$ is the mean of the series is expected as zero,

$$
X_{t}=c+\varepsilon_{t}+\sum_{i=1}^{p} \varphi_{i} X_{t-i}+\sum_{i=1}^{q} \theta_{i} \varepsilon_{t-i}
$$

where $\varphi_{i}, \ldots, \varphi_{p}$ the parameters of the AR model, $\theta_{1}, \ldots, \theta_{q}$ are the parameters of the MA model, $c$ is constant, and $\varepsilon_{t}$ is white noise. The white noise $\varepsilon_{t}$ is independent and has identical probability normal distribution. The model is usually referred to as the $\operatorname{ARMA}(p, q)$ model where $p$ is the order of the autoregressive (AR) part and $q$ is the order of the moving average (MA) part.

The error terms $\varepsilon_{t}$ are generally assumed to be independent identically distributed random variables (i.i.d.) sampled from a normal distribution with zero mean: $\varepsilon_{t} \square \mathrm{N}\left(0, \sigma^{2}\right)$ where $\sigma^{2}$ is the variance.

\subsection{Autoregressive integrated moving average (ARIMA) model}

In statistics and econometrics, and in particular in time series analysis, an autoregressive integrated moving average (ARIMA) model is a generalization of an autoregressive moving average (ARMA) model. Both of these models are fitted to time series data either to better understand the data or to predict future points in the series (forecasting). ARIMA models are applied in some cases where data show evidence of non-stationarity, where an initial differencing step (corresponding to the "integrated" part of the model) can be applied one or more times to eliminate the non-stationarity.

The AR part of ARIMA indicates that the evolving variable of interest is regressed on its own lagged (i.e., prior) values. The MA part indicates that the regression error is actually a linear combination of error terms whose values occurred contemporaneously and at various times in the past. The I (for "integrated") indicates that the data values have been replaced with the difference between their values and the previous values (and this differencing process may have been performed more than once). The purpose of each of these features is to make the model fit the data as well as possible. 
Non-seasonal ARIMA models are generally denoted ARIMA $(p, d, q)$ where parameters $p, d$, and $q$ are non-negative integers, $p$ is the order (number of time lags) of the autoregressive model, $d$ is the degree of differencing (the number of times the data have had past values subtracted), and $q$ is the order of the moving-average model.

The derivation of ARIMA model is described as below procedure.

Given a time series of data $X_{t}$ where $t$ is an integer index and the $X_{t}$ are real numbers. An ARMA $(p, q)$ model is given by Equation (3).

$$
\begin{aligned}
& X_{t}-\alpha_{1} X_{t-1}-\ldots-\alpha_{p^{\prime}} X_{t-p^{\prime}}=\varepsilon_{t}+\theta_{1} \varepsilon_{t-1}+\ldots+\theta_{q} \varepsilon_{t-q} \\
& \left(1-\sum_{i=1}^{p^{\prime}} \alpha_{i} L^{i}\right) X_{t}=\left(1+\sum_{i=1}^{q} \theta_{i} L^{i}\right) \varepsilon_{t}
\end{aligned}
$$

where $L$ is the lag operator, $\alpha_{i}$ are the parameters of the autoregressive part of the model, $\theta_{i}$ are the parameters of the moving average part and $\varepsilon_{t}$ are error terms. The error terms $\varepsilon_{t}$ are generally assumed to be independent, identically distributed variables sampled from a normal distribution with zero mean.

In time series analysis, the lag operator, $L$ or backshift operator operates on an element of a time series to produce the previous element. For example, given some time series:

$$
X=\left\{X_{1}, X_{2}, \ldots\right\}
$$

Then,

$L X_{t}=X_{t-1}$ for all $t>1$.

where $L$ is the lag operator. Note that the lag operator can be raised to arbitrary integer powers so that:

$L^{k} X_{t}=X_{t-k}$

Referring to Equation (4), assume now that the polynomial $\left(1-\sum_{i=1}^{p^{\prime}} \alpha_{i} L^{i}\right)$ has a unit root (a factor $\left.(1-L)\right)$ of multiplicity $d$. Then it can be rewritten as:

$\left(1-\sum_{i=1}^{p^{\prime}} \alpha_{i} L^{i}\right)=\left(1-\sum_{i=1}^{p^{\prime}-d} \alpha_{i} L^{i}\right)(1-L)^{d}$

An ARIMA $(p, d, q)$ process expresses this polynomial factorization property with $p=p^{\prime}-d$, and is given by:

$\left(1-\sum_{i=1}^{p} \phi_{i} L^{i}\right)(1-L)^{d} X_{t}=\left(1+\sum_{i=1}^{q} \theta_{i} L^{i}\right) \varepsilon_{t}$

The Equation (7) can be generalized as follows,

$\left(1-\sum_{i=1}^{p} \phi_{i} L^{i}\right)(1-L)^{d} X_{t}=\delta+\left(1+\sum_{i=1}^{q} \theta_{i} L^{i}\right) \varepsilon_{t}$

This defines an ARIMA $(p, d, q)$ process with drift $\delta /(1-\Sigma \varphi i)$.

\subsection{Diagnostics checking}

The function of diagnostic checking is to determine whether the assumptions underlying the innovation series are satisfied by the residuals of the calibrated autoregressive-moving average (ARMA) or autoregressive integrated moving average (ARIMA) model. Diagnostic checks only have meaning if the parameters of the model are efficiently estimated using the maximum likelihood approach at the estimation stage. For the diagnostic checks in this paper, it is assumed that a maximum likelihood estimator is used to estimate the model parameters. A random pattern of residuals supports a linear model.

The difference between the observed value of the dependent variable $(y)$ and the predicted value $(\hat{y})$ is called the residual $(e)$. Each data point has one residual.

Residual $=$ Observed value - Predicted value

$e=y-\hat{y}$

Both the sum and the mean of the residuals are equal to zero. That is, $\Sigma e=0$ and $\mathrm{e}=0$.

In discrete time, white noise is a discrete signal whose samples are regarded as a sequence of serially uncorrelated random variables with zero mean and finite variance 


\subsection{Currency exchange rate}

\section{RESULT AND DISCUSSIONS}

In this study, data of currency exchange rate which are 1 Malaysian Ringgit (MYR) to United States Dollar (USD) is selected. The period of analysis is determined from January 2010 until April 2017.The analysis is involved with 88 months observations. Figure 1 shows the dynamic movement of currency exchange rate. The maximum value is 0.335 in August 2011. At this point, Malaysian Ringgit currency is strong with respect to USD. Meanwhile, the minimum value is 0.224 in December 2016. At this point, Malaysian Ringgit currency is weak with respect to USD.

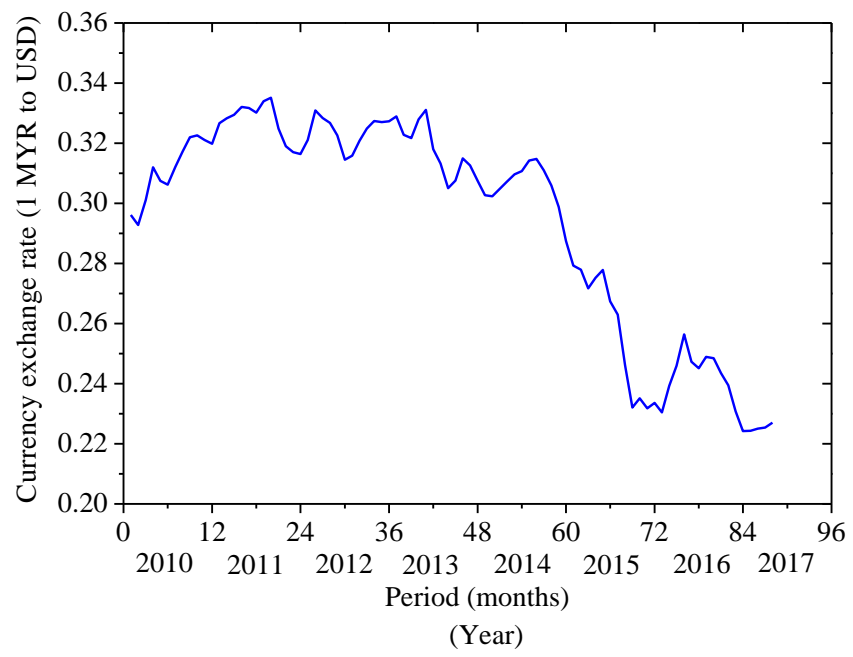

Figure 1: Dynamic currency exchange rate (1 MYR to USD)

Then, this study performed the autocorrelation and partial autocorrelation test. Table 1 shows slow exponentially decay in autocorrelation (AC) value. Therefore, this concluded that this time series data is non-stationary. The mean and variance data of 1 MYR to USD is not constant over time.

Table 1: Autocorrelation and partial correlation analysis

\begin{tabular}{|c|c|c|c|c|c|c|c|}
\hline \multicolumn{8}{|c|}{$\begin{array}{l}\text { Sample: } 2010 \mathrm{M} 01 \text { 2017M04 } \\
\text { Included observations: } 88\end{array}$} \\
\hline Autocorrelation & Partial Co & rrelation & & $\mathrm{AC}$ & PAC & Q-Stat & Prob \\
\hline 1 & 1 & & 1 & 0.967 & 0.967 & 85.180 & 0.000 \\
\hline 1 & 回 & I & 2 & 0.925 & -0.165 & 163.99 & 0.000 \\
\hline 1 & 11 & 1 & 3 & 0.882 & -0.017 & 236.44 & 0.000 \\
\hline 1 & 1 & , & 4 & 0.838 & -0.026 & 302.69 & 0.000 \\
\hline 1 & 1 & 1 & 5 & 0.796 & 0.006 & 363.23 & 0.000 \\
\hline 1 & 1 & 1 & 6 & 0.758 & 0.024 & 418.75 & 0.000 \\
\hline 1 & 1 & 1 & 7 & 0.722 & -0.003 & 469.71 & 0.000 \\
\hline 1 & 1 & 1 & 8 & 0.689 & 0.027 & 516.74 & 0.000 \\
\hline 1 & 1 & I & 9 & 0.660 & 0.027 & 560.45 & 0.000 \\
\hline 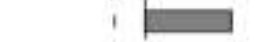 & 1 进 & 1 & 10 & 0.628 & -0.079 & 600.56 & 0.000 \\
\hline
\end{tabular}

\subsection{Differencing currency exchange rate data}

In developing stationary data from non-stationary, one of the common solutions is to use differenced variable for first differences:

$$
\Delta y_{t}=y_{t}-y_{t-1}
$$

where variable $y_{t}$ is value of currency exchange rate at period $t$. The variable $\Delta y_{t}$ is integrated of order one, denoted $I(1)$.

Table 2 shows the autocorrelation and partial correlation analysis for variable $\Delta y_{t}$. Table 2 show the significant spike in autocorrelation diagram. Therefore, the variable $\Delta y_{t}$ is a stationary variable. It is concluded that mean and variance for variable $\Delta y_{t}$ is constant over time. 
Table 2: Autocorrelation and partial correlation analysis

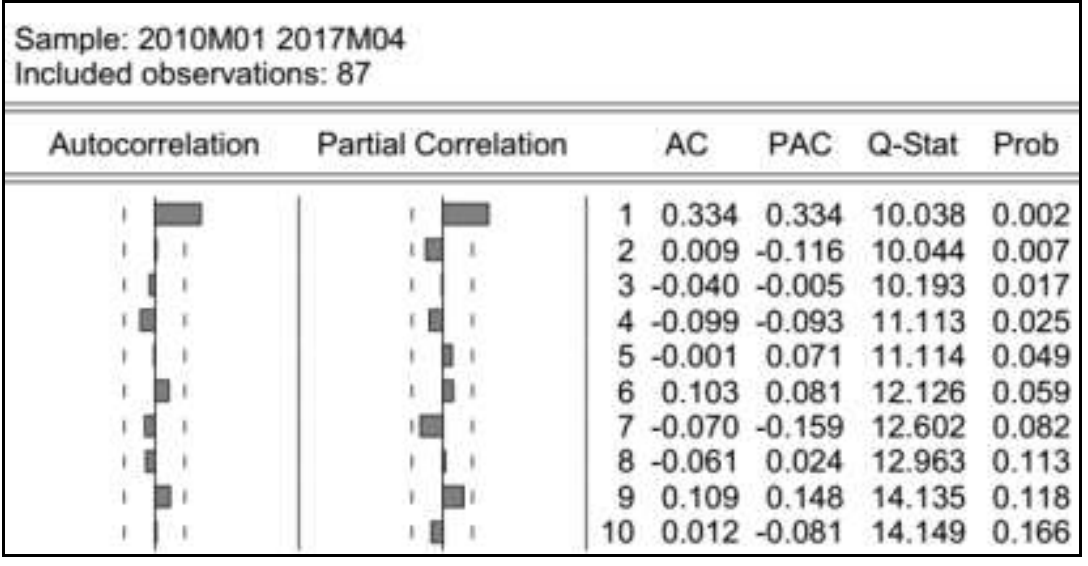

Then, the characteristics of stationary for variable, $\Delta y_{t}$ validated with plotting the dynamic behavior of Integration of order 1, I (1) as shown in Figure 2.The mean is -0.00079 and standard deviation is 0.00562 . Therefore, the variable $\Delta y_{t}$ is validated as stationary variable.

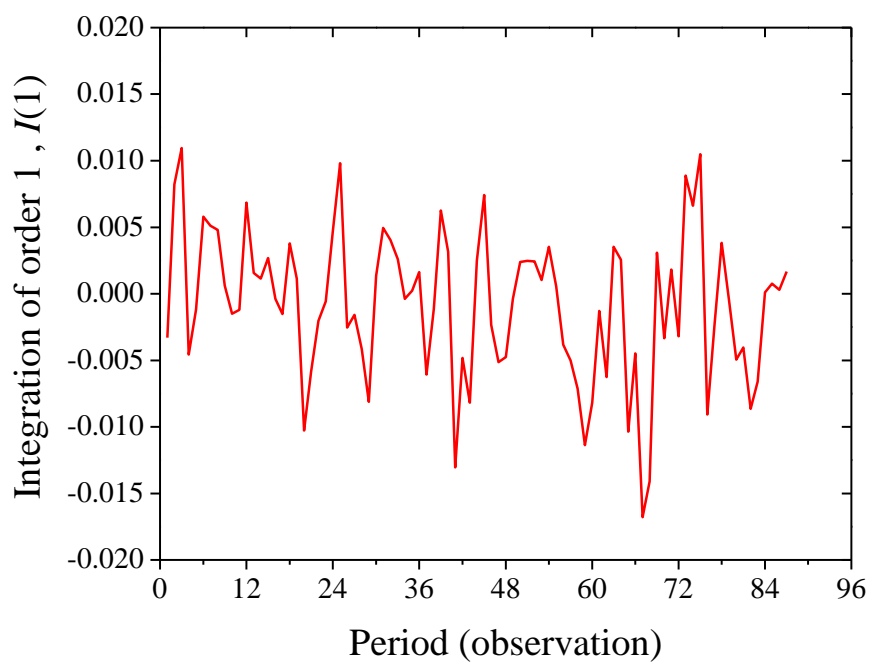

Figure 2: Dynamic behavior of Integration of order 1, I (1)

\subsection{An autoregressive integrated moving average (ARIMA) model}

From correlogram in Table 2, the estimated ARIMA model is ARIMA $(1,1,1)$. Then, ARIMA model for currency exchange rate with first difference is described as next equation:

From equation (8), we define currency exchange rate as $y_{t}$

$$
\left(1-\sum_{i=1}^{p} \phi_{i} L^{i}\right)(1-L)^{d} y_{t}=\delta+\left(1+\sum_{i=1}^{q} \theta_{i} L^{i}\right) \varepsilon_{t}
$$

Therefore, $\operatorname{ARIMA}(1,1,1)$ indicates $p=1, d=1$ and $q=1$. The equation is derived as below procedure:

$$
\begin{aligned}
& \left(1-\phi_{1} L^{1}\right)(1-L) y_{t}=c+\left(1+\theta_{1} L^{1}\right) \varepsilon_{t} \\
& \left(1-\phi_{1} L^{1}\right)\left(y_{t}-y_{t-1}\right)=c+\left(1+\theta_{1} L^{1}\right) \varepsilon_{t}
\end{aligned}
$$




$$
\begin{aligned}
& \left(1-\phi_{1} L^{1}\right) \Delta y_{t}=c+\left(1+\theta_{1} L^{1}\right) \varepsilon_{t} \\
& \Delta y_{t}-\phi_{1} L^{1} \Delta y=c+\varepsilon_{t}+\theta_{1} L^{1} \varepsilon_{t} \\
& \Delta y_{t}-\phi_{1} \Delta y_{t-1}=c+\varepsilon_{t}+\theta_{1} \varepsilon_{t-1} \\
& \Delta y_{t}=c+\phi_{1} \Delta y_{t-1}+\theta_{1} \varepsilon_{t-1}+\varepsilon_{t}
\end{aligned}
$$

From the analysis of data in Table 3 , ARIMA $(1,1,1)$ equation can be represented by below equation:

\begin{tabular}{|c|c|c|c|c|}
\hline \multicolumn{5}{|c|}{$\begin{array}{l}\text { Dependent Variable: D(USDMYR) } \\
\text { Method: ARMA Maximum Likelihood (OPG - BHHH) } \\
\text { Sample: } 2010 \mathrm{M} 022017 \mathrm{M04} \\
\text { Included observations: } 87 \\
\text { Convergence achieved after } 17 \text { iterations } \\
\text { Coefficient covariance computed using outer product of gradients }\end{array}$} \\
\hline Variable & Coefficient & Std. Error & t-Statistic & Prob. \\
\hline $\begin{array}{c}\text { C } \\
\text { AR(1) } \\
\text { MA(1) } \\
\text { SIGMASO }\end{array}$ & $\begin{array}{r}-0.000802 \\
0.028938 \\
0.346519 \\
2.73 E-05\end{array}$ & $\begin{array}{l}0.000825 \\
0.240702 \\
0.227617 \\
4.22 \mathrm{E}-06\end{array}$ & $\begin{array}{r}-0.972586 \\
0.120222 \\
1.522377 \\
6.472023\end{array}$ & $\begin{array}{l}0.3336 \\
0.9046 \\
0.1317 \\
0.0000\end{array}$ \\
\hline $\begin{array}{l}\text { R-squared } \\
\text { Adjusted R-squared } \\
\text { S.E. of regression } \\
\text { Sum squared resid } \\
\text { Log likelihood } \\
\text { F-statistic } \\
\text { Prob(F-statistic) }\end{array}$ & $\begin{array}{l}0.125152 \\
0.093531 \\
0.005350 \\
0.002376 \\
333.5860 \\
3.957864 \\
0.010875\end{array}$ & \multicolumn{2}{|c|}{$\begin{array}{l}\text { Mean dependent var } \\
\text { S.D. dependent var } \\
\text { Akaike info criterion } \\
\text { Schwarz criterion } \\
\text { Hannan-Quinn criter. } \\
\text { Durbin-Watson stat }\end{array}$} & $\begin{array}{r}-0.000794 \\
0.005620 \\
-7.576690 \\
-7.463315 \\
-7.531037 \\
1.992890\end{array}$ \\
\hline $\begin{array}{l}\text { Inverted AR Roots } \\
\text { Inverted MA Roots }\end{array}$ & $\begin{array}{r}.03 \\
-.35\end{array}$ & & & \\
\hline
\end{tabular}

$\Delta y_{t}=-0.000802+0.028938 \Delta y_{t-1}+0.346519 \varepsilon_{t-1}+0.0000273$

Table 3: ARIMA analysis

\subsection{Diagnostics checking}

Then, diagnostics checking was carried out to assess the appropriateness of the model ARIMA $(1,1,1)$ by defining residuals and examining residual plots. Residual is the difference between the observed value of the dependent variable and the predicted value.

Figure 3 shows the residual plot for currency exchange rate in first difference. A residual plot is a graph that shows the residuals on the vertical axis and the independent variable on the horizontal axis. If the points in a residual plot are randomly dispersed around the horizontal axis, a linear regression model is appropriate for the data. Therefore, Figure 3 shows a random pattern of residuals supports a linear model.

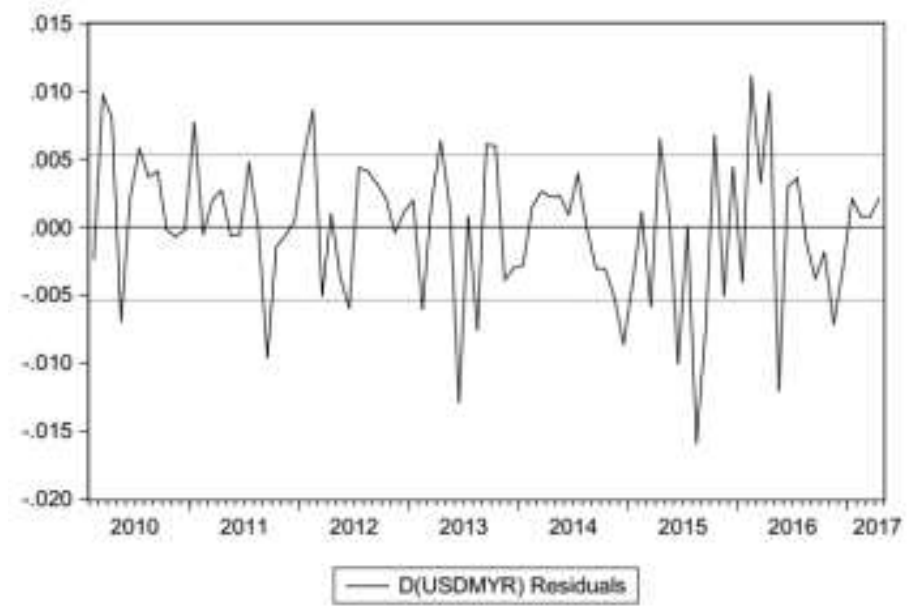

Figure 3: Residual plot for currency exchange rate in first difference

To validate this finding, correlogram for residual was performed. Table 4 shows that ARIMA $(1,11)$ has no significance spike for Autocorrelation function (ACF) and Partial autocorrelation function (PACF).Therefore, the 
residuals estimated are purely random. This implies data of exchange rate currency 1 MYR to USD in first difference are suitable to represent in $\operatorname{ARIMA}(1,1,1)$.

Table 4: Correlogram for residuals analysis

\begin{tabular}{|c|c|c|c|c|c|c|}
\hline \multicolumn{7}{|c|}{$\begin{array}{l}\text { Sample: } 2010 \mathrm{M01} 2017 \mathrm{MO4} \\
\text { Included observations: } 87 \\
\text { Q-statistic probabilities adjusted for } 2 \text { ARMA terms }\end{array}$} \\
\hline Autocorrelation & Partial Correlation & & $A C$ & PAC & Q-Stat & Prob \\
\hline 1 & 1 & 1 & 0.001 & 0.001 & 0.0002 & \\
\hline 1 & 1 & 2 & 0.004 & 0.004 & 0.0020 & \\
\hline & 11, & 3 & -0011 . & .0 .011 & 0.0134 & 0.908 \\
\hline id: & id & 4 & -0.091 & -0.091 & 0.7901 & 0.674 \\
\hline .7. & .71 & 5 & -0.018 & -0.017 & 0.8191 & 0.845 \\
\hline , 吕 & 16 & 6 & 0.139 & 0.141 & 2.6588 & 0.616 \\
\hline (1) & 10 & 7 & -0.092 & -0.096 & 3.4698 & 0.628 \\
\hline 101 & , 目 1 & 8 & -0.081 & -0.094 & 4.1061 & 0.662 \\
\hline 1 . & 当 & 9 & 0.144 & 0.156 & 6.1757 & 0.519 \\
\hline 15. & 15 & 10 & -0.022 & 0.001 & 6.2256 & 0.622 \\
\hline 11 & il i & 11. & -0.039 & -0.070 & 6.3821 & 0.701 \\
\hline in. & 11 & 12 & 0.087 & 0.064 & 7.1637 & 0.710 \\
\hline id. & 18 & 13 & -0.082 & -0.029 & 7.8711 & 0.725 \\
\hline $.7 \%$ & 11, & 14 & -0.011 & -0.004 & 7.8835 & 0.794 \\
\hline 11. & 1 & 15 & 0.050 & -0.008 & 8.1516 & 0.834 \\
\hline 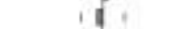 & 11 & 16 & -0.055 & -0.023 & 8.4807 & 0.863 \\
\hline 111 & 111 & 17 & -0.012 & 0.016 & 8.4978 & 0.902 \\
\hline 111 & 111 & 18 & -0.009 & -0.065 & 8.5073 & 0.932 \\
\hline 1 & in & 19 & 0.064 & 0.098 & 8.9677 & 0.941 \\
\hline 11. & 111 & 20 & 0.011 & 0.025 & 8.9620 & 0.980 \\
\hline
\end{tabular}

\section{CONCLUSION}

This research if focus on data clustering using autoregressive integrated moving average (ARIMA) model. The selected data that involved in this study is data of currency exchange rate which are 1 Malaysian Ringgit (MYR) to United States Dollar (USD). The period of analysis is arranged from January 2010 until April 2017.The total observations that involved in this analysis is 88 months observations. The main findings from this study are:

1. The maximum value of currency exchange rate for 1 Malaysian Ringgit (MYR) to United States Dollar (USD) is 0.335 in August 2011. At this point, Malaysian Ringgit currency is strong with respect to USD. Meanwhile, the minimum value is 0.224 in December 2016. At this point, Malaysian Ringgit currency is weak with respect to USD.

2. This study performed the autocorrelation and partial autocorrelation test. Result shows slow exponentially decay in autocorrelation (AC) value. Therefore, this concluded that this time series data is non-stationary. The mean and variance data of 1MYR to USD is not constant over time.

3. Integration of order $1, I(1)$ for exchange rate currency show stationary characteristics. The value of mean is -0.00079 and standard deviation is 0.00562 . Therefore, the Integration of order $1, I$ (1) is validated as stationary variable.

4. $\operatorname{ARIMA}(1,1,1)$ model for currency exchange rate with first difference is described as next equation:

$\Delta y_{t}=-0.000802+0.028938 \Delta y_{t-1}+0.346519 \varepsilon_{t-1}+0.0000273$

5. In diagnostics checking process, correlogram evaluation for residual was performed. ARIMA $(1,11)$ model show no significance spike for Autocorrelation function (ACF) and Partial autocorrelation function (PACF).Therefore, the residuals estimated are purely random. As the conclusion, the data of exchange rate currency 1 MYR to USD in first difference are suitable to represent in model of ARIMA $(1,1,1)$.

The importance of this study is to develop data clustering method for currency exchange rate that can help economists understand the dynamic behavior of currency movement.

\section{FURTHER RESEARCH}

The further research can be implementing in forecasting the future value of currency exchange rate with different data sets. In addition, further research can be implementing in evaluating the determinants that contributes to the behavior of currency exchange rate movement.

\section{REFERENCES}

[1]. Jadevicius, A. and Huston, S. (2015), ARIMA modelling of Lithuanian house price index, International Journal of Housing Markets and Analysis, Vol. 8, Issue 1, pp.135-147.

[2]. Al- Shiab, M. (2006), The Predictability of the Amman Stock Exchange using the Univariate Autoregressive Integrated Moving Average (ARIMA) Model, Journal of Economic and Administrative Sciences, Vol. 22, Issue 2, pp. 17-35.

[3]. Abd Razak, D. and Abdul Karim, M.A. (2008), Development of Islamic Finance in Malaysia: A Conceptual Paper, 8th Global Conference on Business \& Economics, October 18-19th, 2008 Florence, Italy, ISBN: 978-0-9742114-5-9. 
[4]. Zarrouk, H., El Ghak, T. and Al Haija, E.A. (2017), Financial development, Islamic finance and economic growth: evidence of the UAE, Journal of Islamic Accounting and Business Research, Vol. 8, Issue 1, pp.2-22.

[5]. Abu Bakar, N. and Uzaki, K. (2013), An Empirical Study of Initial Public Offerings Underpricing For Shariah-compliant Companies: The Case of Malaysian Market, International Journal of Economics, Business and Finance, Vol. 1, No. 9, October 2013, pp: 262 274.

[6]. Mumtaz Hussain, Asghar Shahmoradi, and Rima Turk (2015), An Overview of Islamic Finance, IMF Working Paper.

[7]. Tsagkanos, A. and Siriopoulos, C. (2013), A long-run relationship between stock price index and exchange rate: A structural nonparametric cointegrating regression approach, International Fin. Markets, Inst. and Money, Vol. 25, pp.106-118.

[8]. Clements, K.W. and Lan Y. (2010), A new approach to forecasting exchange rates, Journal of International Money and Finance, Vol. 29, Issues 7, pp. 1424-1437.

[9]. Meese, R. and K. Rogoff (1983), Empirical Exchange Rate Models of the Seventies: Do They Fit Out of Sample?, Journal of International Economics, Vol. 14, pp. 3-24.

[10]. Balli, F. and Elsamadisy, E.M. (2012), Modelling the currency in circulation for the State of Qatar, International Journal of Islamic and Middle Eastern Finance and Management, Vol. 5, Issue 4, pp. 321-339.

[11]. El-Masry, A. and Abdel-Salam, O. (2007), Exchange rate exposure: do size and foreign operations matter? Managerial Finance, Vol. 33, Issue 9, pp.741-765. 